\title{
A CONSTRUÇÃO DAS IDENTIDADES DOS PROFISSIONAIS DA EDUCAÇÃO
}

Alberto Albuquerque Gomes

Universidade Estadual Paulista - UNESP, Departamento de Educação, Presidente Prudente, SP. Email: albertofctunesp1990@gmail.com

\section{RESUMO}

Este artigo resulta de reflexões durante meu estágio de pós-doutoramento na Universidade Lusófona de Humanidades e Tecnologia, em Lisboa. Me intrigava que mecanismos ou fatores eram determinantes/decisivos na construção da identidade do profissional docente. Aqui exponho um pequeno recorte considerando aspectos relativos à construção das identidades profissionais. Dentre as questões que emergiram de nossa reflexão: que podem ser enumeradas: 1. A enorme dispersão de cursos e de formações iniciais é um componente importante, embora não seja suficiente para explicar o panorama da crise de identidade de professores; 2 . À baixa qualidade da formação inicial pode se atribuir essa inconsistência da identidade profissional; 3 . A indefinição de um campo e de um objeto da pedagogia contribui para essa fragilidade; 4 . Estamos diante de um célere processo de redimensionamento do mundo do trabalho onde as funções e papeis sofrem rápidas transformações descaracterizando as profissões sem que haja a constituição de novas identidades.

Palavras-chave: identidade profissional; identidade de professores; formação inicial.

\section{THE BUILDING OF THE IDENTITIES OF EDUCATION PROFESSIONALS}

\begin{abstract}
This article results from reflections during my post-doctoral training at the Lusophone University of Humanities and Technology, in Lisbon. I was intrigued that mechanisms or factors were decisive / decisive in the construction of the identity of the teaching profession. Here I present a small cut considering aspects related to the construction of professional identities. Among the questions that emerged from our reflection: what can be enumerated: 1 . The enormous dispersion of courses and initial training is an important component, although it is not enough to explain the panorama of the identity crisis of teachers; 2 . The low quality of the initial formation can attribute this inconsistency of the professional identity; 3 . The indefinition of a field and an object of pedagogy contributes to this fragility; 4 . We are faced with a rapid process of resizing the world of work where functions and roles undergo rapid transformations, characterizing the professions without the constitution of new identities.
\end{abstract}

Keywords: professional identity; teacher identity; Initial formation. 
Para quê professores numa sociedade que, de há muito, superou não apenas a importância destes na formação das crianças e dos jovens, mas que também é muito mais ágil e eficaz em trabalhar as informações? E então, para quê formar professores? (PIMENTA, 1997)

O interesse pela temática advém de meu estágio de pós-doutoramento realizado em 2003/2004 na Universidade Lusófona de Humanidades e Tecnologia, em Lisboa, centrado na temática "As representações coletivas como substrato da vida social: identidade profissional, racionalidade e crise identitária do professor".

Nesse momento, me intrigava que mecanismos ou fatores eram determinantes/decisivos/influentes na construção da identidade do profissional docente com o olhar voltado para os cursos de Pedagogia, responsáveis pela formação de professores para as séries/anos iniciais do Ensino Fundamental.

Este artigo apresenta um pequeno recorte considerando aspectos relativos à construção das identidades profissionais considerando a pesquisa principal intitulada "As representações coletivas como substrato da vida social: identidade profissional, racionalidade e crise identitária do professor", desenvolvida ao longo de meu estágio de pós-doutoramento realizado em 2003/2004 na Universidade Lusófona de Humanidades e Tecnologia, em Lisboa - Portugal.

\section{REFLETINDO SOBRE IDENTIDADE}

A construção das identidades dos profissionais da educação teve lugar no ambiente de transformação e de consolidação do paradigma emergente nos séculos XVII e XVIII, no auge da revolução científica, através da ampliação de espaços de atuação dos sujeitos, ou seja, o novo modelo industrial e urbano que exigiu a construção de novas identidades profissionais sustentadas pelo paradigma da racionalidade, distintas daquelas vivenciadas nas corporações de artífices.

Nas palavras de Castells (2003, p. 3), identidade pode ser definida como "[...] o processo de construção do significado com base num atributo cultural, ou ainda, um conjunto de atributos culturais inter-relacionados, o $(\mathrm{s})$ qual (ais) prevalece $(\mathrm{m})$ sobre outras formas de significado [...]".

Para os próprios sujeitos dessa construção, a identidade é um processo de auto representação projetado no outro e ao mesmo tempo fonte de tensão e contradição nas ações sociais desencadeadas no processo de coletivização dos sujeitos (CASTELLS, 2003).

Complementando e ratificando esse raciocínio, Teodoro $(1998$, p. 2$)$ afirma que

A produção das identidades resulta da convergência de dois processos, o biográfico e o relacional. O primeiro, o da identidade para si, decorre no tempo e resulta de uma construção pelos indivíduos de identidades sociais e profissionais a partir das categorias oferecidas por instituições como a família, a escola, o mercado de trabalho ou a empresa, consideradas acessíveis e valorizantes. O segundo, o da identidade para os outros, diz respeito ao reconhecimento das identidades associadas aos saberes, competências e imagens que os indivíduos dão de si próprios nos sistemas de acção em que participam, num dado momento e num determinado espaço de legitimação.

Ou seja, o controle exercido pelos membros das corporações de artífices foi substituído pelo controle de instituições como a família, a escola, o mercado de trabalho através de categorias morais e/ou profissionais, evidenciando a necessidade de que cada sujeito se 'auto represente' inspirado em si, mas projetado no outro, o que indica a tensão e contradição sugerida por Castells (2003).

Essa tensão caracteriza as lutas entre distintos sujeitos sociais que constroem certa visão de mundo, onde estão embutidos princípios, valores e ações. Aprendemos e assimilamos ao longo de nossa trajetória como agir, como esperam que ajamos, como esperamos que os outros ajam e assim modelamos a nós mesmos e ao outro. 
Desde que nascemos, aprendemos o que significa ser mulher ou homem, filho ou pai, estudante ou trabalhador. Assumimos para nós próprios e tornamo-nos naquilo que na nossa sociedade e na nossa cultura se entende ser cada uma dessas coisas. (BRANDÃO; MARQUES; ARAUJO, 2004, p. 7)

Acrescente-se a isso a condição profissional. A construção do trabalhador moderno traz no seu bojo essas condições. Além da construção de novos sujeitos, acreditava-se que a ciência, a educação, a profissionalização e, em geral, a política, o direito e a economia poderiam, aliando racionalidade e fraternidade, realizar a 'perfectibilidade humana' a que se referia Condorcet. (LOPES, 2001, p. 221),

Por outro lado ao ampliar-se o espaço de construção da identidade dos sujeitos, tanto do ponto de vista biográfico como relacional (TEODORO, 1998), a família passa a exercer novos papéis na construção das consciências, assim como o sistema escolar e os locais de trabalho imiscuem-se em espaços antes exclusivos da família, pois segundo Durkheim, deve haver intervenção externa toda vez que a família não consegue cumprir seus deveres. ${ }^{1}$

O mesmo autor, afirma que a educação escolar tem funcionado durante os últimos séculos, mormente no século $X X$, como um mecanismo de controle e de construção das identidades nacionais. $O$ saber, que no ideário iluminista se imagina como emancipador, passa a estar a serviço da regulação e da construção de uma nova ordem social. (DURKHEIM, 1961)

Assim, a escolarização torna-se condição e dispositivo para incorporação do sujeito ao mundo social e do trabalho, o que requer dele (o trabalhador), também uma identidade.

Assumir essa perspectiva de análise implica em considerar que as identidades são construídas no plano das representações sociais e consequentemente, a profissionalização e a construção de identidades específicas para cada tipo de trabalhador parece ser o mecanismo mais eficiente para assegurar o controle dos sujeitos. Segundo Lopes (2001, p. 225),

O profissionalismo, sustentado pela ideologia do liberalismo, liga-se, assim, directamente a uma modificação da estrutura social - baseada na divisão das tarefas sociais e na parcelarização e especialização crescente dos saberes. As "profissões liberais" - baseadas no saber científico-académico e no ideal de serviço - tornam-se o modelo ideal de profissão; foi esse modelo que as teorias funcionalistas da Sociologia das profissões codificaram como tipo profissional ideal, em relação ao qual todas as outras profissões eram classificadas.

Assim sendo, a representação sobre o "ser professor" é vinculada à figura do profissional regulador da ordem social numa dimensão moralizante. Durkheim (1978, p. 54-55) chama a atenção para esse aspecto ao afirmar que

[...] a autoridade moral é a qualidade essencial do educador. Porque, pela autoridade, que nele se encarna, é que o dever é o dever. 0 que o dever tem de especial é o tom imperativo com que fala às consciências, o respeito que inspira à vontade, e que faz inclinar-se, desde que se tenha pronunciado [...] O mestre leigo pode e deve ter alguma coisa desse sentido. Ele também é o órgão de uma grande entidade moral: a sociedade. Da mesma forma que o sacerdote é o intérprete do seu Deus, ele é o intérprete das idéias morais de seu tempo e de sua terra. Que se aferre a essas idéias, que sinta toda a sua grandeza e autoridade que existe nelas e de que ele possua perfeita consciência. Não tardará essa autoridade a comunicar-se à sua pessoa e a tudo quanto dela emane.

O comentário de Durkheim sugere que a profissão docente é uma profissão do tipo burocrática delegada pelo Estado e legitimada pela Sociedade.

\footnotetext{
${ }^{1}$. Durkheim afirma em Educação e Sociologia que a educação é, assim, concebida como uma coisa essencialmente privada e doméstica, tendendose desse ponto de vista, naturalmente, a reduzir ao mínimo a intervenção do Estado. De fato, dizem alguns, só quando falte a família é que o Estado deve intervir, como auxiliar e substituto. Quando a família não está em estado de cumprir os seus deveres, é natural que o Estado apareça. (p. 47). 
Diante do exposto, parece-me que nos defrontamos com a seguinte questão: a profissionalização e a escolarização são exigências da modernidade como forma de inserção dos indivíduos no novo mundo social e ao mesmo tempo de regulação das ações sociais.

Assim, a profissionalização do professor faz parte desse projeto e constituiu-se num dos pilares da construção do poder do Estado moderno. Ou seja, professores tornam-se "funcionários" do Estado moderno, favorecendo e contribuindo para a imposição de normas sociais em detrimento da disseminação do saber.

Esta identidade profissional dilui-se diante de uma mudança sociocultural e política que redefine o papel do Estado (Estado mínimo) e provoca profundo desgaste nas categorias profissionais da modernidade, incluindo a do professor.

Portanto, podemos inferir que do mesmo modo que o professor, durante o processo de construção das identidades profissionais no mundo moderno (inclusive da sua identidade) teve papel preponderante na consolidação da moderna sociedade, também tem sua crise de identidade fortemente marcada pela desconstrução da modernidade e das identidades.

Seria lícito então pensar que, se a crise atinge toda a vida social, nos professores, ela seria particularmente intensa, por ser a sua própria matéria de trabalho que nela está em causa: a possibilidade de transmissão de geração em geração de um modo colectivo credível de ver o mundo. Seria então também possível pensar que é o questionamento que se faz dessa possibilidade que gera, entretanto, outras crises: da escola (enquanto resposta outrora eficaz a um pedido social), dos professores (enquanto grupo social entre outros, seu estatuto e seu poder social) e dos professores como pessoas (sua satisfação e realização pessoais). Nesse contexto, a profissão docente aparecia-nos profundamente ligada à construção da sociedade moderna e a sua crise à desconstrução da modernidade; conseqüentemente, a sua resolução estaria profundamente relacionada com a elaboração de um projecto social alternativo. (LOPES, 2001, p. 21)

Como decorrência da hipótese formulada acima, tal crise pode ser associada ao esgotamento de um modelo de identidade construído com base no paradigma da racionalidade científica emergente a partir da revolução científica dos séculos XVI e XVII tornando-se um modelo global. Ou seja, não só as identidades profissionais se deterioram, mas também o modelo de racionalidade que dirigiu o mundo nos últimos três séculos.

Segundo Lopes (2001, p. 227),

A crise da modernidade é a crise desta normalidade, a que corresponde a mutação sóciocultural tendente a alterar as ênfases que têm sido mais relevantes nos seus dois pilares: 0 Estado, no pilar da regulação, e a racionalidade cognitivo-instrumental, no pilar da emancipação, ambas, como vimos, profundamente relacionadas com os processos de escolarização e profissionalização, os quais se relacionaram, por sua vez, com a emergência da esfera pública clássica. No domínio do trabalho e das profissões, a crise transporta, como já referimos, o desgaste das próprias categorias sócio-profissionais, pelo menos no seu modo de funcionamento identitário clássico, sendo uma das suas importantes conseqüências o deslocamento da problemática identitária do grupo sócioprofissional para os contextos de trabalho, ou ainda, das profissões para a socialização profissional. O uso cada vez mais intenso da noção de identidade profissional por relação com a noção de profissionalismo parece transportar em si esse deslocamento que é também um deslocamento da objectividade para a subjectividade, do nacional para o local, do intergrupal para o interpessoal e do exógeno para o endógeno.

As questões ora propostas constituem-se em ponto de partida para refletir sobre a construção da identidade profissional e o conceito de representações sociais.

Identidade profissional e representações sociais

As questões elencadas no tópico anterior permitem-nos estabelecer algumas relações entre a construção da identidade profissional e representações sociais considerando-as como manifestações de indivíduos e grupos ao longo dos processos comunicacionais que asseguram aos 
sujeitos sociais uma compreensão congruente acerca da realidade social. Ou seja, a inserção dos indivíduos no mundo social e a interação entre os diferentes sujeitos ocorrem com base em sistemas de representações e atitudes (religião, moral, normas jurídicas, educação, identidades e papéis sociais) que asseguram canais de via dupla para a comunicação.

Sobre esses processos, Durkheim (2002) entendia que consistiam em representações coletivas resultantes das relações entre os indivíduos que deveriam ser examinadas distinguindoas dos fenômenos psicológicos de caráter individual, pois, [...] os estados da consciência coletiva são de natureza diferente dos estados da consciência individual; são representações de outra espécie [...] pois [...] o que as representações coletivas traduzem é a maneira pela qual o grupo se enxerga a si mesmo nas relações com os objetos que o afetam. (DURKHEIM, 1977, p. 26).

Como exemplo, podemos citar a linguagem ou práticas de trabalho desenvolvidas no interior de uma dada sociedade, produtos reais das relações sociais. Ou seja, representações decorrentes das relações estabelecidas entre indivíduos ou entre grupos secundários são formuladas frequentemente pelos sujeitos para dar sentido à vida social.

Portanto, essas representações não podem ser tomadas como práticas simples e elementares da vida social, uma vez que há uma multiplicidade de elementos que interferem direta e indiretamente na construção dessas representações sobre o mundo sensível. Papéis sociais relativos a atividades de natureza jurídica, científica, econômica dentre outras atividades remetem-nos para a representação do que seja profissão e das identidades de cada profissão, uma vez que fazem parte dos sistemas de representações que, como já mencionado, permeiam a vida social, dando-lhe sentido.

Como se vê, o conceito de representação social não pode ser simplificado a ponto de ser considerado como uma simples imagem da realidade refletida nos membros da sociedade como se fosse um espectro. Uma representação social possui uma força que repercute de maneira significativa na constituição do indivíduo e do sujeito social reforçando comportamentos socialmente aceitos e reprovando comportamentos inadequados.

Desse ponto de vista, a construção da identidade profissional do professor pode ser compreendida como processo de inserção e aceitação social.

Quando Durkheim (1978) ressalta que o papel profissional do professor no mundo moderno está qualificado pela autoridade moral que lhe é conferida pelo grupo social ao qual se destina, e pela sua própria crença (do professor) da relevância dessa autoridade, podemos entender que há então uma simbiose entre a biografia individual e os aspectos relacionais. Ou seja, a identidade do professor é definida pela sua aceitação enquanto tal e pela aprovação da sociedade ou grupo social no qual está inserido. Estamos falando, portanto, da formação de grupos profissionais com identidades específicas, que tendem a se agrupar na forma de associações ou corporações, constituindo-se em forças coletivas capazes de organizar e administrar a vida social, muito embora isso não signifique neutralizar as ações individuais.

Sobre esse aspecto, Durkheim (1967) ao reapresentar sua obra "La división del trabajo social" alerta para o papel dos grupos profissionais, que apesar do caráter rudimentar de sua moral e consciência social, assumiam crescente importância na vida social, sugerindo que a profissão poderia vir a ser herdeira da ordem familiar como elemento de reconstrução da moralidade e da solidariedade da sociedade industrial. Podemos falar então, que o grupo profissional de professores enquanto grupo permanente e duradouro tem como papel social fundamental a transmissão do cabedal cultural acumulado pelas gerações anteriores bem como assegurar a perpetuação de determinadas regras da vida social, tais como a moral e autoridade.

\section{CRISE DE IDENTIDADE OU CRISE DA FORMAÇÃO DE PROFESSORES}

Os anúncios feitos ao longo desse texto sobre a constituição das identidades nos sugerem uma reflexão sobre qual seria o "nó górdio" desse processo. 
O estudo e a análise desse tema passam necessariamente pela formação de professores, e exige que pensemos detidamente para tentar compreender as expectativas e representações sobre a formação desses profissionais e a constituição de suas identidades.

Ao considerar os cursos de formação de professores em nosso pais, especialmente, para as séries iniciais do Ensino Fundamenta, quando nos referimos a esse espaço de formação e nos remetendo a Leite e Lima (2010) observamos que

Segundo dados do INEP/MEC, no ano de 2006, havia 1.731 cursos de Pedagogia no Brasil. Entretanto, no desenvolvimento da pesquisa foram encontrados apenas 1.424 cursos em funcionamento. Observamos que alguns cursos estavam em processo de extinção e constatamos que o mesmo curso aparecia duas ou três vezes no site do INEP/MEC. Na análise dos dados da Região Sudeste, nos anos de 2006 e 2008, ocorreu o mesmo fato. De acordo com o site INEP/MEC, havia nessa região, em 2006, 641 cursos, mas trabalhamos com 551 e, em referência a 2008, havia 853 cursos de Pedagogia, dos quais consideramos, para a pesquisa, 731 .

Pimenta et al (2017, p. 28) acrescenta ainda que

As matrizes curriculares dos cursos de pedagogia refletem os mesmos problemas identificados nas DCN, ou seja, a indefinição do campo pedagógico e a dispersão do objeto da pedagogia e da atuação profissional docente. Consequentemente, a maioria desses cursos não dão conta de formar nem o pedagogo, nem, tampouco, o professor para os anos iniciais da educação básica e para a educação infantil.

Evidentemente que essa enorme dispersão de cursos e de formações iniciais não são suficientes para explicar o panorama da crise de identidade de professores, mas seguramente nos propõe questões tais como: à dispersão e baixa qualidade da formação inicial pode se atribuir essa inconsistência da identidade profissional? A indefinição de um campo e de um objeto da pedagogia contribuiria para essa fragilidade? Ou estamos diante de um célere processo de redimensionamento do mundo do trabalho onde as funções e papeis sofrem rápidas transformações descaracterizando as profissões sem que haja a constituição de novas identidades?

\section{REFERÊNCIAS}

ANTUNES, R. \& ALVES, G. As mutações no mundo do trabalho na era da mundialização do capital. Educação e Sociedade, Campinas, vol. 25, n. 87, p. 335-351, maio/ago2004. Disponível em $<$ http://www.cedes.unicamp.br>. Consultado em 30 de maio de 2006.

CASTELLS, M. O poder da identidade. Lisboa, Fundação Calouste Gulbenkian, 2003.

CORTESÃO, L. Ser professor: um ofício em risco de extinção? São Paulo : Cortez/IPF. 2002.

DUBAR, C. A crise das identidades: A interpretação de uma mutação. São Paulo: Edusp, 2009.

DURKHEIM, E. Sociologia, educação e Moral. (Trad. Evaristo Santos). Porto: RES - Editora. 1961. Sociologia e Filosofia. Rio de Janeiro: Forense, 1977.

- Educação e sociologia. 3. ed. Tradução de Lourenço Filho. São Paulo: Melhoramentos, 1978. . Lições de Sociologia. São Paulo; Martins Fontes: 2002. 
GOMES, A. A. A construção da identidade profissional do professor: uma análise de egressos do curso de Pedagogia. Anais do VI Congresso Português de Sociologia, 2008. Disponível em <http://www.aps.pt/vicongresso/pdfs/590.pdf>. Consultado em 02/04/2013.

LEITE, Y. U. F; LIMA, V. M. M. Cursos de Pedagogia no Brasil: o que dizem os dados do Inep/Mec? Ensino Em-Revista, Uberlândia, v.17, n.1, p. 69-93, jan./jun.2010.

LOPES, A. Professora e identidade: Um estudo sobre a identidade social de professores portuguesas. Porto: ASA, v.25. 2001 (Cadernos Investigações e práticas)

PIMENTA, S. G. Formação de professores - saberes da docência e identidade do professor. In: Nuances, Vol. III, setembro de 1997

; FUSARI, J. C.; PEDROSO, C. C. A; PINTO, U. A. Os cursos de licenciatura em pedagogia: fragilidades na formação inicial do professor polivalente. Educ. Pesqui., São Paulo, v. 43, n. 1, p.15-30, jan./mar. 2017.

TEODORO, A. Professores, para quê? Lisboa: Profedições, 2006. 